\title{
THE ROLE OF CORPORATE AGREEMENT AS A LEGAL MECHANISM FOR REGULATING CORPORATE RELATIONS UNDER THE CIVIL LEGISLATION OF THE RUSSIAN FEDERATION
}

\author{
Elmira F. Baibekova \\ Astrakhan State University, Astrakhan, Russian Federation
}

\begin{abstract}
Introduction: the paper is devoted to the study of the institution of corporate agreement incorporated into the Russian legislation in the course of the civil law reform. The purpose is to determine the essence, meaning and basic characteristics of the corporate agreement in civil law of Russia, by virtue whereof, the author analyzes the concept of subject of the corporate agreement, the main aspects of its legal nature, and also produces a comparative legal analysis of the correlation of the company's charter and the corporate agreement. Using the methods of scientific knowledge, especially the method of system analysis, in order to identify the areas of improvement of the corporate agreement in the field of regulating corporate rights and obligations, the author analyzes the corporate agreement's role in the implementation and protection of the company's corporate rights, as well as in the development of corporate relations. The necessity of further detailed legislative regulation of corporate agreements is argued. Results: the legal confirmation of the institution of corporate agreement in the civil legislation of the Russian Federation allowed the participants of business companies to implement and control their corporate rights and obligations, as well as liability for their non-performance, in accordance with this agreement. Conclusions: corporate agreement is a relatively new institution for the Russian reality, so it requires special attention. It is of great interest to business, which can be seen in practical examples, even the largest corporations with the state participation become parties to such agreements. The need for a detailed study of the corporate agreement is due to the ambiguous position of the legislator regarding the essence, meaning and content of this agreement. The absence of a solid theoretical basis on these issues can have a very negative impact on the law enforcement practice.
\end{abstract}

Key words: legal entity, corporation, charter, corporate agreement, corporate legal relations, company member, corporate rights and obligations.

Citation. Baibekova E.F. The Role of Corporate Agreement as a Legal Mechanism for Regulating Corporate Relations under the Civil Legislation of the Russian Federation. Legal Concept, 2019, vol. 18, no. 4, pp. 99-104. (in Russian). DOI: https://doi.org/10.15688/lc.jvolsu.2019.4.13

\section{РОЛЬ КОРПОРАТИВНОГО ДОГОВОРА КАК ПРАВОВОГО МЕХАНИЗМА РЕГУЛИРОВАНИЯ КОРПОРАТИВНЫХ ОТНОШЕНИЙ ПО ГРАЖДАНСКОМУ ЗАКОНОДАТЕЛЬСТВУ РОССИЙСКОЙ ФЕДЕРАЦИИ}

\section{Эльмира Фаридовна Байбекова}

Астраханский государственный университет, г. Астрахань, Российская Федерация

Введение: в данной статье анализируется институт корпоративного договора, систематизированного в законодательство Российской Федерации в ходе преобразования гражданского законодательства. Цель состоит в определении сущности, значения и основных признаков корпоративного договора в гражданском 
праве России, в связи с этим автор анализирует понятие предмета корпоративного договора, основные аспекты его правовой природы, а также проводит сравнительно-правовой анализ соотношения устава общества и корпоративного договора. С помощью методов научного познания автором в целях выявления направлений совершенствования корпоративного договора в области регулирования корпоративных прав и обязанностей была проанализирована роль корпоративного соглашения в реализации и защите корпоративных прав участников общества. Результаты: закрепление корпоративного договора как института гражданского законодательства Российской Федерации дало возможность участникам обществ осуществлять и контролировать корпоративные права и обязанности, а также ответственность за их неисполнение в соответствии с данным договором. Выводы: корпоративный договор для российской действительности относительно новый институт, поэтому требует к себе особого внимания. Он представляет огромный интерес для бизнеса, что можно увидеть на практических примерах, членами таких соглашений становятся даже крупнейшие корпорации с государственным участием. Необходимость детального изучения корпоративного договора обусловлена неоднозначной позицией законодателя относительно сущности, значения и содержания данного соглашения.

Ключевые слова: юридическое лицо, корпорация, устав, корпоративный договор, корпоративные правоотношения, участник общества, корпоративные права и обязанности.

Цитирование. Байбекова Э. Ф. Роль корпоративного договора как правового механизма регулирования корпоративных отношений по гражданскому законодательству Российской Федерации // Legal Concept = Правовая парадигма. - 2019. - Т. 18, № 4. -C. 99-104. - DOI: https://doi.org/10.15688/lc.jvolsu.2019.4.13

\section{Введение}

После того как 1 сентября 2014 г. вступили в действие изменения в гражданском законодательстве, возникла ситуация, при которой значительные преобразования произошли в общей части ГК РФ. В качестве одного из наиболее существенных изменений, наступивших в результате принятия рассматриваемого кодифицированного акта, предстает факт закрепления на правовом уровне понятия «корпоративный договор». Положения ст. 67.2 ГК РФ регламентируют, что в процессе осуществления хозяйственной деятельности участникам хозяйственного общества предоставляется право на заключение между собой корпоративного договора, в котором стороны будут договариваться о реализации своих корпоративных прав. Вместе с тем после введения преобразований сложилась ситуация, когда большое количество спорных ситуаций возникло в аспекте определения предмета, сторон, правовой природы рассматриваемого типа договорного акта ввиду рецепции рассматриваемого института, а также в силу того, что в настоящее время еще не сложилась единообразная арбитражная судебная практика.

Если обратиться к анализу современного института корпоративного права, можно выяснить, что в качестве ключевого элемента данного института выступает корпоратив- ный договор, так как он представляет собой один из наиболее значимых источников регулирования, который пусть не является нормативным источником, но при этом в нем заложены основные правила поведения, которые предполагается в дальнейшем множество раз применять на практике всем членам корпоративного образования [1, с. 121].

\section{Правовая природа корпоративного договора по гражданскому праву РФ}

Видные представители науки корпоративного права заняли весьма разнообразные позиции по вопросу определения сущности предмета корпоративного договора. Подобная ситуация обусловлена тем, что долгий период времени отсутствует устоявшаяся практика применения данного института, а также ситуацию усугубляет то, что правовая природа корпоративного договора отличается своим двойственным характером. В результате, по мнению некоторых ученых, предмет корпоративного договора есть не что иное, как исключительно корпоративный элемент. В частности, Д.В. Ломакин придерживается позиции, в соответствии с которой структура предмета корпоративного договора содержит комплекс действий, совершаемых корпорациямиучастницами в рамках реализации делегированных им корпоративных прав по определен- 
ной схеме, а также включает в себя бездействия, которые могут быть выражены в том, что стороны принимают решение воздержаться от реализации на практике имеющихся у них корпоративных прав [6, с. 14-16].

Мы считаем, что наиболее аргументированной является позиция, которую заняли В.П. Камышанский [3, с. 22] и Ю.Г. Лескова. Ученые расценивают корпоративный договор как единственный тип договора, который не может быть включен в группы договоров гражданско-правового характера общецелевого назначения, а в качестве фундаментальной основы данного типа договора выступает синаллагматический критерий [5, с. 108]. Необходимо также указать, что корпоративный договор в качестве своего предмета определяет обязанность участников субъекта хозяйственной деятельности реализовать свои права корпоративного порядка по определенной модели. Согласно положениям, регламентированным в ст. 2 ГК РФ, в категорию взаимоотношений, подлежащих регламентации со стороны гражданского законодательства, следует включить только те из них, что возникают в процессе участия в деятельности корпоративных организаций и в процессе управления, после чего на законодательном уровне закрепляется наименование данных взаимоотношений - «корпоративные отношения».

Корпоративный договор отличается тем, что ему присущ обязательственный характер, так как он может быть заключен в результате влияния общего принципа свободы догово$\mathrm{pa}$, и он непосредственно регламентирован в рамках положений ст. 67.2 ГК РФ. В соответствии с положениями п. 1 ст. 67.2 ГК РФ в качестве сторон договора признаются участники хозяйственного общества. При этом положения ст. 9 ФЗ от 26 декабря 1995 г. № 208-Ф3 и ст. 7 ФЗ от 8 февраля 1998 г. № 14-Ф3 прово3глашают, что учредителями (участниками) хозяйственного общества закон признает юридических и физических лиц.

При этом в качестве сторон корпоративного договора могут выступить не только участники хозяйственного общества. Если обратиться к анализу содержания п. 3 ст. 67.2 ГК РФ, можно заключить, что кредиторам и другим третьим лицам, имеющим определенный интерес в реализации договора, предоставля- ется право на его заключение с участниками хозяйственного общества, и в соответствии с положениями данного соглашения участники хозяйственного общества возлагают на себя обязанность по реализации делегированных им корпоративных прав по определенной модели. Регламентация корпоративных прав и обязанностей осуществлена в нормах п. 1 ст. 67.2 ГК РФ. Перечень корпоративных прав и обязанностей на сегодняшний день не является исчерпывающим, подобный вывод сделан на том основании, что в рассматриваемом пункте присутствует ссылка на возможность его расширения путем включения в формулировку пункта словосочетания «в том числе».

Существует также определенная ссылка, которая содержится в предисловии к письму Центробанка от 10 апреля 2014 г. № 06-52/ 2463 «О Кодексе корпоративного управления» [7]. В ней говорится о том, что в рамках реализации практической деятельности в целях урегулирования корпоративного поведения данная деятельность должна создавать условия, при которых акционеры получат реальную возможность реализовать на практике свои корпоративные права, касающиеся участия в деятельности акционерного общества.

Кроме того, корпоративные права регламентируются также и в положениях абз. 5 ст. 2 Ф3 от 22 апреля 1996 г. № 39-Ф3 «О рынке ценных бумаг» [10], согласно которым понятие «акция» используется в целях регламентации прав, связанных с получением в ходе деятельности акционерного общества определенной доли прибыли, облаченной в форму дивидендов, прав на участие в процессе управления деятельностью акционерного общества, а также прав на определенную долю имущества, которая должна быть оставлена после ликвидации.

Таким образом, резюмируя представленную выше информацию, можно сделать вывод о том, что наряду с правами и обязанностями, которые регламентируются на законодательном уровне в п. 1 ст. 67.2 ГК РФ, положения действующих нормативно-правовых актов содержат в себе ссылки на иные права и обязанности корпоративного характера. В результате осуществления реформаторской деятельности для внесения изменений в структуру гражданского законодатель- 
ства, связанной с внесением корректив и дополнений в положения гл. 4 ГК РФ, возникла ситуация, при которой значимость корпоративного договора как одного из методов урегулирования взаимоотношений между участниками хозяйственного субъекта в существенной мере повысилась.

\section{Роль корпоративного договора в реализации прав и интересов участников общества}

На современном этапе развития общества корпоративный договор также играет одну из самых существенных ролей, так как в качестве аргументов, свидетельствующих о необходимости функционирования института корпоративного договора в российской правовой системе, выступают соображения практического порядка. Прежде всего, современные акционерные общества остро нуждаются в том, чтобы в нашей стране функционировала действенная система корпоративного управления, а также в разработке эффективного механизма, который позволит не допустить развитие определенных типов корпоративных конфликтов. Участники корпоративного общества испытывают острую потребность в том, чтобы их интересы были надлежащим образом осуществлены, а для реализации делегированных им прав корпоративного характера была создана необходимая фундаментальная основа.

Участникам хозяйственного общества предоставляется право на заключение между собой корпоративного договора, в предложениях которого будут рассматриваться аспекты реализации делегированных им корпоративных прав и корпоративных обязанностей. И в данном случае в качестве разновидности корпоративного договора необходимо рассматривать договор о реализации прав участников ООО и акционерное соглашение участников (акционеров) АО [2].

В соответствии с положениями Ф3 «Об акционерных обществах» акционерное соглашение следует анализировать как договор, в котором рассматривается порядок осуществления прав, удостоверенных акциями, а также ряд характерных особенностей осуществления прав на акции. В обусловленных ситуаци- ях в положениях акционерного соглашения может регламентироваться обязанность по согласованию варианта отдачи своего голоса с другими акционерами, обязанность осуществлять процедуру приобретения или отчуждения акций по заранее зафиксированный цене или в результате наступления некоторых обстоятельств, обязанность, предполагающая необходимость воздержаться или отказаться от реализации процедуры отчуждения акций до того момента, пока не наступят некоторые регламентированные в соглашении обстоятельства, обязанность по согласованной реализации других действий, которые демонстрируют взаимосвязь с процессом управления деятельностью общества, реорганизацией и ликвидацией [9].

Акционерное соглашение составляется в единичном экземпляре, форма составления письменная. Для его заключения необходимо составить документ и подписать его сторонами, после чего такое соглашение становится обязательным к исполнению для сторон договора.

Практический опыт функционирования отечественной правовой системы свидетельствует о том, что на сегодняшний день имеются определенные вопросы, на которые необходимо получить ответы в процессе признания недействительности решения органа хозяйственного субъекта, если отмечается, что данное решение вступает в противоречия с требованиями акционерного соглашения. Выполнение этого правила на практике может быть реализовано при соблюдении условия, в соответствии с которым в момент принятия рассматриваемого решения в качестве сторон соглашения выступали все участники общества. Принимая во внимание тот факт, что акционерные, то есть корпоративные правоотношения на сегодняшний день развиваются весьма динамично, возникает ситуация, при которой обстоятельства, ввиду наличия которых было заключено акционерное соглашение, с течением времени могут претерпеть существенные, а порой и кардинальные изменения [8, с. 99]. Кроме того, требуется акцентировать внимание на том, чтобы надлежащим образом рассмотреть ограничения, накладываемые на предмет соглашения. В частности, если обратиться к нормам ФЗ «Об акционер- 
ных обществах», ГК РФ и пунктам 4.1.11 Концепции развития гражданского законодательства РФ, можно обозначить, что вышеназванные правовые акты закрепляют в качестве предмета соглашения следующие его виды: согласованное голосование участников АО; право или обязанность приобретения и реализации акций; обновление запрета на передачу акций; установление обязанности по осуществлению передачи участникам соглашения дивидендов или других видов выплат [4]. В конечном итоге следует особо подчеркнуть, что в результате выполнения мероприятий, в соответствии с которыми данная возможность заключения акционерного соглашения или корпоративного договора будет закреплена на законодательном уровне, подобное нововведение может оказать положительное воздействие на процесс функционирования самого общества, а также будет разработана эффективная система защиты и практической реализации корпоративных прав акционеров, что в итоге не сможет не оказать благотворного воздействия на развитие института корпоративных взаимоотношений.

\section{Выводы}

Резюмируя итоги по результатам проведенного анализа, можно заключить, что в сущности корпоративный договор представляет собой один из наиболее эффективных на сегодняшний день инструментов для управления деятельностью хозяйственного общества со стороны его участников, что предполагает реализацию действий на совместной основе. Иными словами, корпоративный договор в соответствии с его условиями предполагает согласованное использование и распоряжение комплексом делегированных участникам общества корпоративных прав. Положения корпоративного договора не регламентируют структурную организацию и границы компетенции органов субъекта хозяйственной деятельности. Для регламентации указанных вопросов в структуре действующего законодательства имеются определенные положения, а также регламентация осуществляется положениями устава хозяйственного общества. Здесь также необходимо принимать во внимание тот факт, что может существовать только один устав общества и несколько видов корпоративных договоров.

Прошло 5 лет с момента включения в ГК РФ статьи 67.2. В течение этого достаточно продолжительного периода российские суды в рамках реализации практической деятельности приняли несколько прецедентных решений, вызывающих особый интерес. В результате можно сделать вывод о том, что, несмотря на наличие некоторых недостатков, существующий на сегодняшний день механизм функционирования данных договоров демонстрирует достаточно высокий уровень эффективности.

\section{СПИСОК ЛИТЕРАТУРЫ}

1. Андреев, В. К. Корпоративное право современной России : монография. -2-е изд. / В. К. Андреев, В. А. Лаптев. - М. : Проспект, 2017. - 352 с.

2. Гражданский кодекс Российской Федерации (часть первая) от 30.11.1994 № 51-Ф3 : (ред. от 18.07.2019) // Собрание законодательства Российской Федерации. - 1994. - № 32. - Ст. 3301.

3. Камышанский, В. П. Корпоративный договор: юридическая сущность, некоторые проблемы и тенденции / В. П. Камышанский // Актуальные проблемы реформирования гражданского и предпринимательского права : материалы Всерос. очнозаочной науч.-практ. конф. с иностранным участием. - Краснодар : Рос. гос. ун-т правосудия, 2015. C. 21-26.

4. Концепция развития гражданского законодательства Российской Федерации : (одобрена решением Совета при Президенте РФ по кодификации и совершенствованию гражданского законодательства от 07.10.2009) // Вестник ВАС РФ. - 2009. № 11 (ноябрь).

5. Лескова, Ю. Г. Договор как средство саморегулирования предпринимательских отношений / Ю. Г. Лескова // Вестник Академии права и управления. - 2012. - № 27. - С. 107-115.

6. Ломакин, Д. В. Договоры об осуществлении прав участников хозяйственных обществ как новелла корпоративного законодательства / Д. В. Ломакин // Вестник Высшего Арбитражного Суда Российской Федерации. - 2009. - № 8. - С. 6-26.

7. Письмо Банка России от 10.04.2014 № 06-52/ 2463 «О кодексе корпоративного управления» // Вестник Банка России. - 2014. - № 40.

8. Рожкова, М. А. Отдельные аспекты доказывания существенного изменения обстоятельств (по статье 451 ГК РФ) / М. А. Рожкова // Вестник ВАС РФ. - 2001. - № 4. - C. 98-104. 
9. Федеральный закон от 26.12.1995 № 208-Ф3 «Об акционерных обществах» : (ред. от 15.04.2019) // Собрание законодательства Российской Федерации. - 1996. - № 1. - Ст. 1.

10. Федеральный закон РФ от 22.04.1996 №39-Ф3 «О рынке ценных бумаг» : (ред. от 26.07.2019) // Собрание законодательства Российской Федерации. - 1996. - № 17. - Ст. 1918.

\section{REFERENCES}

1. Andreev V.K., Laptev V.A. Korporativnoe pravo sovremennoy Rossii: monografiya [Corporate Law of Modern Russia: monograph]. Moskow, Prospekt Publ., 2017. 352 p.

2. Grazhdanskiy kodeks Rossiyskoy Federatsii (chast pervaya) ot 30.11.1994 № 51-FZ: (red. ot 18.07.2019) [Civil Code of the Russian Federation (Part One) dated November 30, 1994 No. 51-FZ: (as amended on July 18, 2019)]. Sobranie zakonodatelstva Rossiyskoy Federatsii [Collection of Legislation of the Russian Federation], 1994, no. 32, art. 3301.

3. Kamyshansky V.P. Korporativnyy dogovor: yuridicheskaya sushchnost, nekotorye problemy i tendentsii [Corporate Agreement: Legal Nature, Some Problems and Trends]. Aktualnyye problemy reformirovaniya grazhdanskogo i predprinimatelskogo prava: materialy Vserossiyskoy ochno-zaochnoy nauchno-prakticheskoy konferentsii s inostrannym uchastiyem [Actual Problems of the Reform of Civil and Business Law: Materials of the All-Russian Part-Time Scientific-Practical Conference with Foreign Participation]. Krasnodar, Rossiyskiy gosudarstvennyy universitet pravosudiya, 2015, pp. 21-26.

4. Kontseptsiya razvitiya grazhdanskogo zakonodatelstva Rossiyskoy Federatsii (odobrena resheniyem Soveta pri Prezidente RF po kodifikatsii i sovershenstvovaniyu grazhdanskogo zakonodatelstva ot 07.10.2009) [The Concept of Development of Civil Legislation of the Russian Federation (Approved by the Decision of the Council under the President of the Russian Federation on the Codification and Improvement of Civil Legislation of 07.10.2009)]. Vestnik
$V A S R F$ [VAS Bulletin of the Russian Federation], 2009, no. 11 (November).

5. Leskova Yu.G. Dogovor kak sredstvo samoregulirovaniya predprinimatelskikh otnosheniy [The Contract as a Means of Self-Regulation of Entrepreneurial Relations]. Vestnik Akademii prava $i$ upravleniya [Bulletin of the Academy of Law and Management], 2012, no. 27, pp. 107-115.

6. Lomakin D.V. Dogovory ob osushchestvlenii prav uchastnikov khozyaystvennykh obshchestv kak novella korporativnogo zakonodatelstva [Contracts on the Exercise of the Rights of Participants in Business Entities as a Novelty of Corporate Legislation]. Vestnik Vysshego Arbitrazhnogo Suda Rossiyskoy Federatsii [Bulletin of the Supreme Arbitration Court of the Russian Federation], 2009, no. 8, pp. 6-26.

7. Pismo Banka Rossii ot 10.04.2014 № 06-52/ 2463 «O kodekse korporativnogo upravleniya» [Letter of the Bank of Russia dated 10.04.2014 No. 06-52 / 2463 "On the Corporate Governance Code" ]. Vestnik Banka Rossii [Bank of Russia Bulletin], 2014, no. 40.

8. Rozhkova M.A. Otdelnyye aspekty dokazyvaniya sushchestvennogo izmeneniya obstoyatelstv (po statye 451 GK RF) [Some Aspects of Proving a Significant Change in Circumstances (under Article 451 of the Civil Code of the Russian Federation)]. Vestnik VAS [Bulletin of the Supreme Arbitration Court of the Russian Federation], 2001, no. 4, pp. 98-104.

9. Federalnyy zakon ot 26.12.1995 № 208-FZ «Ob aktsionernykh obshchestvakh»: (red. ot 15.04.2019) [Federal Law of December 26, 1995 No. 208FZ “On Joint-Stock Companies": (as amended on April 15, 2019)]. Sobranie zakonodatelstva Rossiyskoy Federatsii [Collection of Legislation of the Russian Federation], 1996, no. 1, art. 1.

10. Federalnyy zakon RF ot 22.04.1996 № 39-FZ «O rynke tsennykh bumag»: (red. ot 26.07.2019) [Federal Law of the Russian Federation of 04.22.1996 No. 39-FZ "On the Securities Market": (as amended on 07.26.2019)]. Sobranie zakonodatelstva Rossiyskoy Federatsii [Collection of Legislation of the Russian Federation], 1996, no. 17, art. 1918.

\section{Information about the Author}

Elmira F. Baibekova, Candidate of Sciences (Jurisprudence), Associate Professor, Department of Corporate Law, Astrakhan State University, Tatishcheva St., 20A, 414056 Astrakhan, Russian Federation, karinbey@mail.ru, https://orcid.org/0000-0003-4955-4293

\section{Информация об авторе}

Эльмира Фаридовна Байбекова, кандидат юридических наук, доцент кафедры корпоративного права, Астраханский государственный университет, ул. Татищева, 20A, 414056 г. Астрахань, Российская Федерация, karinbey@mail.ru, https://orcid.org/0000-0003-4955-4293 